\title{
e-interview
}

\section{Patrick McGorry}

Patrick McGorry is Professor of Psychiatry at the University of Melbourne and Director of ORYGEN Youth Health in the same city. He studied at the Universities of Sydney, Melbourne and Monash University. He trained in Australia and the UK. His special interests include preventive psychiatry, youth and refugee mental health and psychosis.

\section{If you were not a psychiatrist, what} would you do?

I would have liked to be a musician or perhaps a writer (I would have been impoverished, however).

What has been the greatest impact of your profession on you personally? The close contact with seriously mentally ill patients, and the opportunity to understand and help them to overcome this massive challenge and threat. The experience of helping people recover and to see that this is more readily achievable than is generally believed. I have met inspiring people - patients, relatives and colleagues.

\section{Do you feel stigmatised by your} profession?

Not at all. I am very proud to be a psychiatrist and feel very fortunate indeed.

\section{What are your interests outside of work?}

Sport: surfing, skiing, Australian football; Music. My children and their interests.

What job gave you the most useful training experience?

The opportunity to develop a clinical research team and model of care and research when I set up a first episode research programme during my higher training period (1984-6).

\section{Which books have influenced you most?}

Warner, R. (1986) Recovery from Schizophrenia. London. Routledge; Mrazek, P. J. \& Haggerty, R. J. (eds) (1994) Reducing Risks for Mental Disorders: Frontiers for Preventive Intervention Research. Washington, DC: National Academy Press.

What part of your work gives you the most satisfaction?

Clinical practice with young people with psychotic disorders and their families.

\section{What do you least enjoy?}

Trying to engage bureaucrats who have no commitment to their area of responsibility.

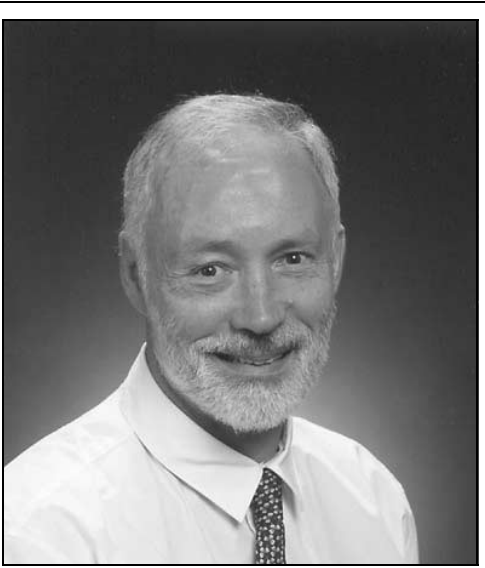

and the lifestyle benefits, as well as the unique privileges and opportunities psychiatry and psychiatry research bring. If the morale in the profession improved and confidence grew then this would help. We need to be more powerful in the array of medical specialities too. All these variables are correlated of course. More confidence, selling our value and opportunities: and perhaps we should also stoop to pointing out the boring realities of some of the other career options in medicine?

What is the most important advice you could offer to a new trainee?

Find a good mentor(s). Find your niche and learn to understand yourself. Try to develop and maintain a stable and nurturing personal life and working environment. Be

What is the greatest threat facing the profession?

The increasing materialism and selfishness of western society, which is probably not only a risk factor for increasing mental disorders but also a threat to effective treatments.

\section{What single change would} substantially improve quality of care? Population-wide awareness, not only of the true burden of disease associated with mental disorders, but also of the poor access and quality of treatment even in our affluent world. In our consumer society, this recognition might drive reform and investment on the basis of self-interest in parallel with logic and altruism. Greater unity within the mental health field would also help.

\section{What conflict of interest do you} encounter most often?

A conflict between partly external pressure to keep clinical budgets more or less within limits and the desire to respond in a timely manner to the high levels of demand for our services. This is a structural problem, which affects mental health more seriously than other branches of medicine in the developed world.

\section{Do you think psychiatry is brainless or} mindless?

think in the UK it tends to be a bit less mindful than in Australia since psychotherapy seems more split off from general psychiatry there. In the US it has clearly moved from being brainless to mindless. In other countries the position on this spectrum seems to vary. Obviously both extremes are highly adverse for patient care.

How would you entice more medical students into the profession? It needs to be marketed aggressively with good role models (patients or users could help to sell it also), stressing the rewards about your patients! Help them to believe in themselves. Try to reinvent things periodically or change your role in some way over time.

What are the main ethical problems that psychiatrists will face in the future?

The dominance of biological psychiatry, especially in the USA means that many of the human issues are overshadowed. Ironically, more so perhaps, in psychiatry even than in the rest of medicine. This may flow into genetic research where the fluid boundary between health and disease in psychiatry poses more problems ethically than say in diabetes or cancer. Another is the excessive development of a forensic mentality and the inappropriate incarceration of many (young) people with mental health problems and disorders especially in the UK and the USA.

How would you improve clinical psychiatric training?

Much more psychotherapy training for UK psychiatrists. More community-based experience as well.

What single change to mental health legislation would you like to see? Make it much more difficult for patients to be referred to secure forensic units for relatively minor offences.

What single area of psychiatric Health Services Research and the development of novel interventions of all types.

What single area of psychiatric practice is most in need of development?

Youth mental health / preventive psychiatry.

Dominic Fannon yourself and respect and find things to like research should be given priority? 